\title{
Spinal hydatid disease
}

Sertaç Ișlekel ${ }^{1}$, Yusuf Erşahin² ${ }^{2}$, Mehmet Zileli ${ }^{3}$, Nezih Oktar $^{2}$, Kazim Öner ${ }^{2}$, İzzet Övül ${ }^{3}$, Nurcan Özdamar ${ }^{3}$ and Erdem Tunçbay ${ }^{4}$

${ }^{1}$ Assistant Professor; ${ }^{2}$ Associate Professor; ${ }^{3}$ Professor; ${ }^{4}$ Professor and Head, Department of Neurosurgery, Ege University Faculty of Medicine, Bornova, İzmir, Turkey

Vertebral hydatid cysts are rare and found in less than $1 \%$ of all the cases of hydatidosis. Neural compression is common in vertebral hydatidosis. The prognosis is generally regarded as very poor. This paper examines the natural history and complications which may arise during the treatment of vertebral hydatid cyst, and discusses their treatment. Thirteen cases of hydatid disease affecting the vertebrae are presented. The patients were admitted with symptoms of spinal cord compression. Twelve were treated by laminectomy and one by costotransversectomy. Low back pain radiating to the legs and lower extremity weakness were the predominant symptoms. Different degrees of pareses were present in 12 patients. Nine patients had impaired sensation in lower extremities. In 13 patients, 27 operations were performed. The major complication of surgery was the death of one patient due to the formaline irrigation. The surgical goal should be an extensive removal of the cysts and affected bone. The surgical area needs to be irrigated with hypertonic saline. Mebendazole or albendazole therapy seems to retard the recurrences and control the disease.

Keywords: echinococcus; hydatid cyst; vertebral hydatid cyst; spinal cord compression

\section{Introduction}

Hydatid disease of the spine, a primary infestation of the larvae Echinococcus granulosus, is characterized by a multivesicular infiltration of the cancellous bone, involving the vertebral bodies, pedicles and laminae to a varying extent. ${ }^{1}$ Spinal hydatid cysts are rare and comprise only $1 \%$ of the patients with hydatid disease. ${ }^{2}$ Successful treatment of the vertebral hydatidosis represents a challenge due to its invasive feature. It is nowadays believed that from the onset of spinal involvement, an average life expectancy is 5 years. The poor prognosis is being compared with that of spinal malignancy. ${ }^{3}$

This rare disease in the United States and West Europe is prevalent especially among sheep raising farmers in Mediterranean, East European, Asian, African and South American countries. ${ }^{4}$ In this paper, we report on 13 cases of spinal hydatid cyst and discuss the epidemiology, diagnosis, treatment and complications while reviewing the literature.

\section{Patients and methods}

During the past 21 years (from January 1975 to June 1996), 13 patients who underwent surgery for spinal space occupying lesions were diagnosed as hydatid-cyst in the Department of Neurosurgery, Ege University

Correspondence: S Ișlekel, MD Department of Neurosurgery, Ege University Faculty of Medicine, Bornova, Izmir 35100 Turkey
Hospital, Izmir, Turkey. There were eight females $(61.5 \%)$ and five males (38.5\%), aged between 16 and 59 years (mean, 38 years). Plain X-ray films, myelography, computed tomography (CT), CT-myelography and magnetic resonance imaging (MRI) were the diagnostic modalities depending on the years of admission to the hospital.

The surgical technique was a decompressive laminectomy in most of the cases. The objective was to remove all cysts and involved bone. But this was almost impossible in most cases. Since the microvesicles are spread diffusely in bone and paravertebral muscles, they are inevitably ruptured during the excision. For that reason one must feel the normal bone demarcation while removing the involved bone. The epidural area and paravertebral muscles should be inspected. Despite all these efforts it is not possible to evacuate all cysts in most of the cases. To prevent cyst recurrence, exposed area were irrigated with hypertonic saline that osmotically disrupts residual cysts. In one of the cases costotransversectomy was preferred since the cyst was located anterior to the vertebral body.

Since the intradural recurrences are the reason of a bad prognosis, attention should be paid not to open or tear the dura.

Clinical symptoms and signs, radiological investigations, and operative techniques were reviewed. Each patient was also evaluated in terms of outcome, recurrence, and postoperative complications. Follow- 
up of the patients ranged from 2 months to 240 months (mean 51.5 months). Three patients were lost to follow-up after 2 months.

\section{Results}

\section{Symptom and signs}

Lower extremity weakness (12 cases) and low back pain radiating to the legs (11 cases) were the predominant symptoms. Urinary hesitancy or incontinence (nine cases), impairment of sensation and paresthesias (nine cases) followed those in order of frequency. Other neurological findings are shown in Table 1.

\section{Radiological investigations}

Plain X-ray films were performed in all patients. There were pedicle erosions in two, and compression fractures of vertebral bodies in four patients. Myelography was performed in seven patients in which a complete blockage of the contrast medium was determined in six. In one patient, myelography showed multiple intradural round shaped lesions masquerading arachnoid cysts. On CT scan of seven patients, erosions of the vertebral bodies and vertebral arches were noticed (Figure 1). MRI was performed in three patients and showed extradural cystic lesions eroding the vertebral bodies and obliterating the spinal canal (Figure 2).

\section{Operative findings}

Twenty-seven operations were performed on 13 patients in our clinic. Six of those patients had previous operations before admission to our clinic. All of the patients underwent at least one surgical intervention. Eight patients underwent multiple operations. One patient was operated on eight times, three patients four times and four patients twice. In 12 patients, the operative technique was a total laminect-

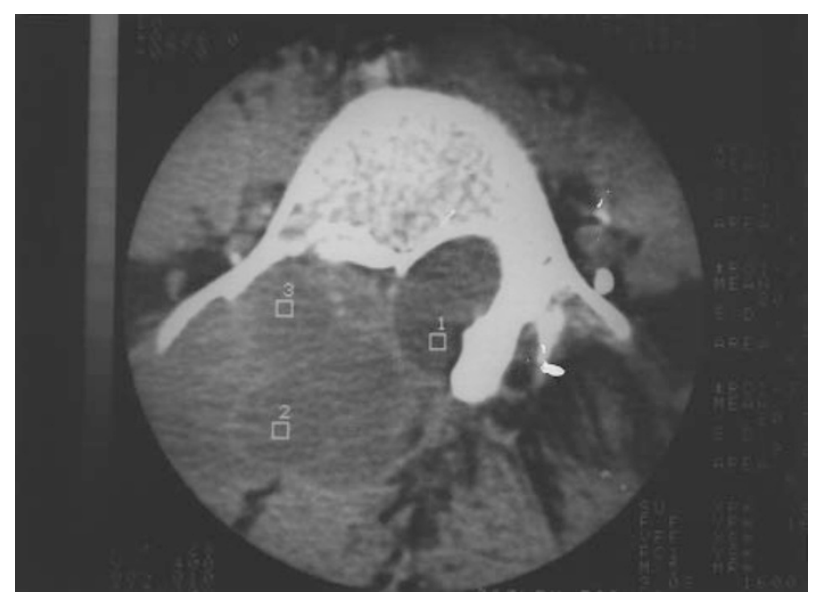

Figure 1 Lumbar computed tomography scan showing pedicle and lamina erosion and invasion of the vertebra with epidural paravertebral cysts

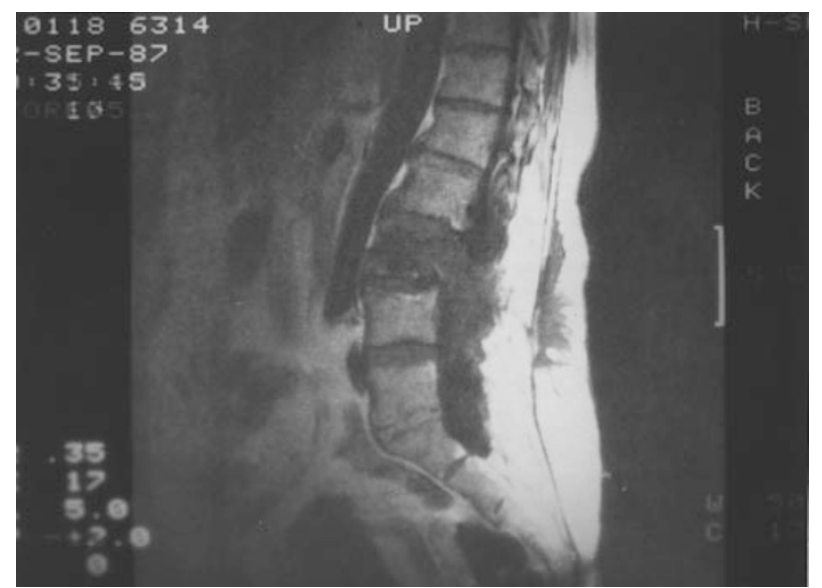

Figure 2 Lumbar magnetic resonance imaging showing vertebral, epidurally located cystic lesions

Table 1 Presenting symptoms and neurological signs of the patients with spinal hydatid disease

\begin{tabular}{|c|c|c|c|c|c|c|c|c|c|c|c|c|c|}
\hline Case & 1 & 2 & 3 & 4 & 5 & 6 & 7 & 8 & 9 & 10 & 11 & 12 & 13 \\
\hline Sex & $\mathrm{F}$ & $\mathrm{F}$ & $\mathrm{F}$ & $\mathrm{F}$ & M & $\mathrm{F}$ & M & $\mathrm{M}$ & M & $\mathrm{F}$ & $\mathrm{F}$ & $\mathrm{F}$ & M \\
\hline Age (yrs) & 46 & 51 & 59 & 24 & 54 & 51 & 16 & 17 & 19 & 25 & 55 & 55 & 24 \\
\hline $\begin{array}{l}\text { Duration of symptoms } \\
\text { (weeks) }\end{array}$ & 28 & 16 & 572 & 156 & 8 & 24 & 8 & 6 & 12 & 12 & 18 & 3 & 6 \\
\hline Back pain & + & + & + & + & - & + & + & + & + & + & + & - & + \\
\hline Radicular pain & + & + & + & + & - & - & + & - & + & - & + & - & + \\
\hline $\begin{array}{l}\text { Level of sensory } \\
\text { disturbances }\end{array}$ & $\mathrm{T} 10$ & No & S1 & No & $\mathrm{T} 10$ & $\mathrm{~T} 10$ & L1 & No & L3 & $\mathrm{T} 10$ & L2-4 & No & T9 \\
\hline Paraparesis & + & + & + & - & + & + & + & + & + & + & + & + & + \\
\hline $\begin{array}{l}\text { Urinary hesitancy or } \\
\text { incontinence }\end{array}$ & - & - & - & + & + & + & + & + & + & + & + & $\begin{array}{c}+ \\
\text { Lung }\end{array}$ & - \\
\hline Systemic hydatid disease & No & Kidney & Kidney & Liver & No & No & Lung & No & No & Lung & No & Liver & No \\
\hline Level of spinal lesion & T12-L1 & L1 & T12-L3 & L4-S1 & T2-T7 & T9-T11 & L1-L3 & T12-L3 & T12-L2 & $\mathrm{T} 10$ & L2-L4 & T7-T9 & T9 \\
\hline
\end{tabular}

F: Female, M: Male 
omy, and in another one a costotransversectomy. In two patients, multiple cysts were seen in the vertebral muscles below the muscle fascia. In one of the cases, cysts were located intradurally. In the others intradural spreading of cysts were seen during the reoperation and if the dura had been opened during the previous operations.

In one of the patients (patient no 3 Table 2), the first operation was performed in a western country where the hydatid disease is not endemic. The pre- and postoperative diagnoses were a dermoid cyst. Opening of the dura during the first operation presumably led to the intradural invasion and recurrences. This patient was operated upon eight times and died of renal complications.

\section{Complications}

The major complication during spinal hydatid cyst surgery was the death of one patient due to the formaline irrigation (patient no 4 Table 2), used to prevent hydatid cyst recurrences. Dural tear, which was developed during the operation of this patient caused intradural penetration of the formaline. Otherwise, irrigation with hypertonic saline, used during the surgery of intradural recurrences did not cause any complication.

Rupture of the cysts during extirpation cannot be regarded as a complication, since it is almost always impossible to remove the cysts without rupture. Consequently nine of the 13 patients needed multiple operations due to the recurrences. Postlaminectomy instability had not been detected in any patient.

\section{Outcome}

Nine patients had one or more recurrences. The shortest and longest time intervals between the recurrences were 2 months and 48 months (mean 25.2 months), respectively. Two deaths occurred in 13 patients. One patient died of complications of the renal hydatid disease. The other mortality was due to the formalin irrigation at surgery. Intradural penetration of formalin presumably led to a toxic myelitis and respiratory arrest. Irrigation of the surgical area with $10 \%$ formaline solution is performed when the cyst ruptures during cranial cyst hydatid surgery. However, it can be very dangerous in spinal hydatid disease when the dura is not intact. The longest follow up period is 240 months. This patient was operated upon four times. With the use of mebendazole therapy, periodic controls of serological tests, neurological and radiological examinations did not show any abnormality as long as 108 months.

\section{Discussion}

In 1964, Rayport ${ }^{5}$ reported a case of vertebral Echinococcosis in detail and made a review of the literature. Vertebral echinococcosis is rare in developed

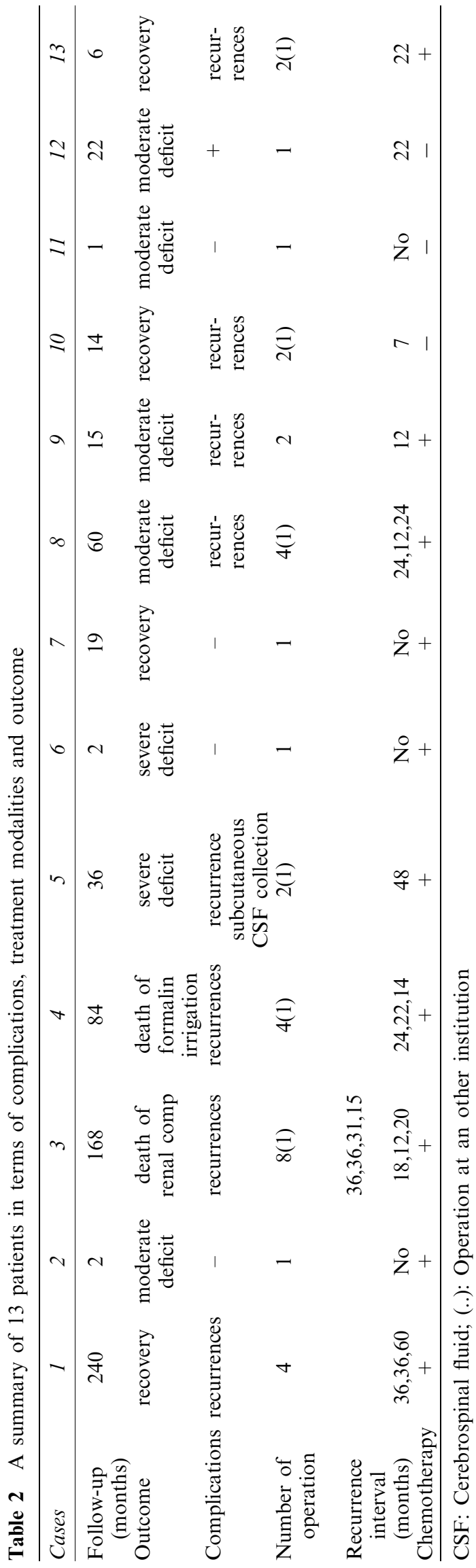


countries. In our clinical series, $13(2.9 \%)$ of the 503 patients operated upon for a spinal cord compression were hydatid cysts. This rate is close to $3.8 \%$ of Pamir et $a l,{ }^{6}$ lower than those of North African and East Asian countries and higher than those of North American and West European countries. ${ }^{4,6,7}$ Such cases may be more frequently seen in developed countries, because of the frequent travel and migration.

Osteohydatidosis was first described by Bidloo $^{8}$ in 1708 , and the first spinal hydatid disease by Chaussier ${ }^{9}$ in 1807 . Besides, Reydellet ${ }^{10}$ in 1819 reported the first surgical intervention in spinal hydatidosis. Ollivier ${ }^{11}$ differentiated between the sources of subarachnoid and epidural infestation. Colman ${ }^{12}$ reported 24 cases of spinal cord compression caused by Echinococcus cysts.

Most spinal lesions are hydatid cysts primarily involving the body of vertebrae as a result of portovertebral shunts. ${ }^{13}$ When echinoccocal embryo is carried to a vertebral body the parasite grows multilocularly along the bony intratrabecular space, infiltrates and destroys the bone like a tumor, because of a lack of defensive reaction of the bony tissue. $5,14,15$ Progressive extension from the vertebral centrum eventually may lead to the invasion of the pedicles and the laminae, although the latter may sometimes be the primary site. Vertebral lesions differ from cerebral lesions in that they are microvesicular and invasive. The natural fate of an untreated cyst may involve calcification and death of the cyst. More frequently, the cyst gradually enlarges. ${ }^{2,16}$

In 1928 Dew $^{17}$ has classified spinal hydatid cysts into five groups: Primary cysts of the spinal cord (intramedullary hydatid cysts), primary intradural cysts (intradural extramedullary hydatid cysts), primary extradural cysts, hydatid cysts of the vertebra and paravertebral lesions extending to the spinal column.

Paravertebral lesions may be located in costal, mediastinal or retroperitoneal regions or in erector spinae muscles. ${ }^{5,14}$ Two $(15.3 \%)$ of our cases had thoracic cysts extending to the spinal column. The incidence of intradural and intramedullary hydatid cysts are less than $1 \%$ in hydatidosis. ${ }^{18-21}$ One of the cases $(7.7 \%)$ was a primary intradural cyst misdiagnosed as multiple intradural arachnoid cysts before the operation. In six patients $(46 \%)$ kidney, liver or pulmonary cysts were found and four of them had been previously operated upon before the admission to our hospital. In all cases vertebral involvement is thought to be mostly thoracic $(50 \%), 20 \%$ in sacral area, $29 \%$ in the lumbar area. Although less common cervical involvement may occur. ${ }^{14,19}$ In our series, six cases $(46 \%)$ had thoracic, three $(23 \%)$ thoracolumbar, three $(23 \%)$ lumbar and one $(8 \%)$ lumbosacral hydatid cysts (Table 1).

The clinical aspect of spinal hydatid cyst is not different from the other spinal cord compression diseases. ${ }^{5,16}$ Grisel and Deve ${ }^{22}$ stated radicular pain as the first complaint. In our cases, back pain in 11 $(85 \%)$ and lower extremity weakness in $10(77 \%)$ patients were the main complaints and radicular pain was present in only $8(62 \%)$ patients. Mean duration of the complaints was 65 weeks, (longest 572 weeks). Six $(46 \%)$ of the patients had previously undergone surgery for their vertebral cysts.

In the literature, $20 \%$ of patients are said to have trauma previously. In our cases only one patient $(8 \%)$ was admitted to the hospital after a lumbar trauma with lumbar vertebral compression fracture and paraplegia. All of the patients in this series presented with severe neurological deficits. Eight $(62 \%)$ had sphincter disturbances and $12(93 \%)$ had different degrees of paraparesis.

For the diagnosis, as in other spinal diseases, plain $\mathrm{X}$-ray films of the spine were the first choice in all cases. In plain X-ray films the pedicle erosion and loss of vertebral body height were mostly seen. ${ }^{23}$ Myelography fails to demonstrate the nature and the pre- or paravertebral involvement of the disease. It only shows an extradural lesion, blocking the subarachnoid space. Koutzanis et $a l^{16}$ have shown an accidental puncture of a paravertebral cyst and its diagnostic value. Myelography can be hazardous, since the puncture of a cyst may lead to the intradural spreading of the disease.

CT scans have the great value for demonstrating body, pedicle and lamina erosions without a subperiostal reaction. Cysts located at paravertebral or epidural area and within the spinal canal can be seen. ${ }^{13}$ The vertebra involved by the disease displays irregular erosions of the cancellous bone. Spread of the lesion towards the periphery of the vertebral body results in a clear-cut erosion of the cortex. There is neither subperiosteal bone formation nor enlargement of the whole bony structure. ${ }^{24}$

The best diagnostic tool seems to be MRI, because it can give the full image in the vertical axis of the spinal canal and thus reveals the full spinal extent of the disease. ${ }^{21,25}$ It can be helpful for planning of the operation. In the two of our cases, the MRI scans clearly showed the site and extent of the cystic lesions and moreover the origin of the cysts. On T1-weighted images, the viable cysts appeared to contain low intensity fluid with iso- to mildly hyperintense cyst walls. On T2-weighted images, a decrease in hyperintensity and an increase in hypointensity from collapsed wall were the findings of a succumbed cyst.

The choice of treatment was surgery in all the cases. Operative procedure was a laminectomy in general. Most of our cases were operated on 10 to 20 years ago. Our present opinion is the most extensive removal of the infected bone must be the goal of the surgery. For lesions situated at the vertebral body, an anterior approach or a costotransversectomy must be used more extensively as described by Baysefer et al. ${ }^{26}$ During operation, the extradural multiple cysts, or cysts located in the bone or in the paravertebral area were seen. Daughter cysts may form within the main cyst. $^{2,27}$ It is impossible to remove these cysts without rupture. During laminectomy, cysts are almost always 
ruptured. Because of impractical total removal, recurrence is inevitable. To prevent recurrence, irrigation with hypertonic saline is recommended. Sometimes, against saline irrigation recurrence cannot be prevented. Formalin irrigation $(10 \%)$ was used for the recurrent cases, as it was performed during the cerebral ruptured hydatid cyst surgery. Formalin irrigation caused the death due to the chemical myelitis in one case in which the dura had been opened.

Seven patients received mebendazole $(50 \mathrm{mg} / \mathrm{kg} /$ day) and two patients albendazole $(10 \mathrm{mg} / \mathrm{kg} /$ day $)$ treatment. Of those nine patients, six had systemic hydatid disease. Two patients with systemic hydatid disease had no recurrence, whereas four had recurrences. One case with four times recurrences is cured with most extensive operation possible and additional mebendazole therapy under serologic control. This patient has no recurrence since 108 months.

\section{Conclusions}

When a cystic lesion is detected on a CT or MRI scan, hydatid cyst should be taken into consideration in countries where hydatid disease is endemic. In this situation a needle biopsy should obviously not be performed, since this would possibly disseminate the disease, especially along the biopsy tract. The most possible extensive removal of the cysts should be the surgical goal, besides removing the affected bone. The surgical area needs to be irrigated with hypertonic saline. If the dura is not opened, formalin $10 \%$ can be used as well. For the cases in which dura is opened only hypertonic saline can be used. ${ }^{28}$ Mebendazole or albendazole therapy seems to retard the recurrences and control the disease. With all the treatment modalities this benign disease has a malignant course, because of its high rate of recurrence.

\section{References}

1 Turtas S, Viale S, Pau A. Long-term results of surgery for hydatid disease of the spine. Surg Neurol 1980; 13: 468-470.

2 Charles RW, Govender S, Naidoo KS. Echinococcal infection of the spine with neural involvement. Spine 1988; 13: 47-49.

3 Fitzpatrick SC. Hydatid disease of the lumbar spine. J Bone Joint Surg 1965; 47A: 286-291.

4 Erșahin Y, Mutluer S, Güzelbağ E. Intracranial hydatid cysts in children. Neurosurgery 1993; 33: 219-225.

5 Rayport M, Wisoff HS, Zaiman H. Vertebral echinococcosis. $J$ Neurosurg 1964; 21: 647-659

6 Pamir MN, Akalan N, Özgen T, Erbengi A. Spinal hydatid cyst. Surg Neurol 1984; 21: 53-57.
7 Battaieb A, Khaldi T, Ben Rhouma T, Touibi S. L'echinococcose vertebromedullaire. Neurochirurgie 1978; 24: 205-210.

8 Bidloo G. Exercitationum anatomico-chirurgicarum decades duae. Lugd. Bat.: J Luchtmans 1708; 216 pp (see pp. 10-26) (Cited in Rayport M, Wisoff HS, Zaiman H (1964) Vertebral echinococcosis. J Neurosurg 1964; 21: 647-659.)

9 Chaussier. Un cas de paralysie des membres inférieurs. $J$ Méd Chir Pharmacol 1807; 14: 231 - 237 in (Rayport M, Wisoff HS, Zaiman H (1964) Vertebral echinococcosis. J Neurosurg 1964; 21: 647-659.)

10 Reydellet. Moelle épiniere, medulla spinalis ou dorsalis. In: Dictionaire des médicales, par une sociétéde médecins et des chirurgiens. Paris: C.I.F. Panckoucke 1819; 33: $538-568$ in (Rayport M, Wisoff HS, Zaiman H. Vertebral echinococcosis. $J$ Neurosurg 1964; 21: $647-659$.)

11 Ollivier CP. Traitédes maladies de la moelle épiniere. Paris: Méquignon-Marvis Pere \& fils, 3rd ed. 1937; 2: $527-550$ in (Rayport M, Wisoff HS, Zaiman H. Vertebral echinococcosis. $J$ Neurosurg 1964; 21: $647-659$.)

12 Colman WS. Hydatid cyst of the spinal canal causing paraplegia. St. Thomas Hosp Rep 1899; 28: $361-380$ (Cited in Rayport M, Wisoff HS, Zaiman H. Vertebral echinococcosis. J Neurosurg 1964; 21: $647-659$.)

13 Iplikçioğlu AC et al. Spinal invasion of pulmonary hydatidosis: Computed tomographic demonstration. Neurosurgery 1991; 29: $467-468$.

14 Özek MM. Complications of central nervous system hydatid disease. Pediatr Neurosurg 1994; 20: 84-91.

15 Tekkök IH, Benli K. Spinal extradural hydatid disease: Report of a case with magnetic resonance characteristics. Neurosurgery 1993; 33: 320 - 323.

16 Kaoutzanis M, Anagnostopoulos D, Apostolou A. Hydatid disease affecting the vertebrae. Acta Neurochir (Wien) 1989; 98: $60-65$.

17 Dew HR. Hydatid disease. Its pathology, diagnosis and treatment. Sydney: Australasian Medical Publishing Co Ltd, p429, 1928.

18 Akhan $\mathrm{O}$ et al. Spinal intradural hydatid cyst in a child. The British J of Radiology 1991; 64: 465-466.

19 Göçer AI et al. Cervical intradural extramedullary hydatid cyst. Turk Neurosurg 1994; 4: 169-171.

20 Medjek L, Zenini S, Hammoum S, Hartani M. Hydatidose intradurale rachidienne dorsale. A propos d'un cas. Ann Radiol 1991; 34: $251-255$.

21 Sharma A, Kashyapbraham J, Kurian S. Intradural hydatid cysts of the spinal cord. Surg Neurol 1981; 16: 235-237.

22 Grisel P, Dévé F. L'abces ossifluent hydatique d'origine vertébrale. Le mal de Pott hydatique. Rev Chir Paris 1929; 67: $375-453$

23 Arana-Iniguez R: Echinococcus, in Vinken PJ, Bruyn GW (eds). Handbook of Clinical Neurology. North Holland, Amsterdam, vol. 35, pp. $175-208,1978$.

24 Pau A et al. Computed tomography and magnetic resonance imaging in spinal hydatidosis. Surg Neurol 1987; 27: 365-369.

25 Özer F, Özek M, Pamir N, Erzen C. Magnetic resonance imaging in the diagnosis of spinal hydatid cyst disease. Case report. Paraplegia 1993; 31: $338-340$.

26 Baysefer A et al. Hydatid disease of the spine. Spinal Cord 1996; 34: $297-300$.

27 Sharma A, Abraham J. Multiple giant hydatid cysts of the brain. J Neurosurg 1981; 57: 413-415.

28 Wani MA et al. Primary spinal extradural hydatid cyst. Neurosurgery 1989; 24: 631-632. 